\title{
FIELD ABLATION AS CULTURAL CONTROL FOR BUNCH MOTH Tirathaba mundella INFESTATION IN YOUNG MATURE OIL PALM
}

\author{
SU CHONG MING*; JOSEPH BONG CHOON FAH ${ }^{\star \star}$ and KHAIRULMAZMI AHMAD
}

\begin{abstract}
The oil palm bunch moth, Tirathaba mundella, is becoming an oil palm bunch feeding pest of significant economic importance especially on peat soil in Sarawak. The goal of this research was to investigate the cultural control effect of field ablation on heavily infested young mature oil palm planted on peat by T. mundella. From the field census carried out at bimonthly interval after three rounds of field ablation, the ablated fields consistently showed significantly high new T. mundella infestation, $41.63 \%$ at week 20, $13.24 \%$ at week 28 and $7.68 \%$ at 36 weeks after three rounds of field ablation for oil palm fruit bunches category as compared to only $17.21 \%, 4.78 \%$ and $4.55 \%$ in the control fields within the same monitoring period. Besides that, the mean larvae count obtained from ablated fields at week 20 was 28.68 which was also significantly higher than that obtained from the control field at only 12.84 larvae. At week 20, the mean T. mundella larvae count and mean percentage of new infestation in ablated plots were $123.44 \%$ and 141.89\% higher than control, respectively. Both detailed field census and random field sampling results suggested that there was no significant effect of three rounds of field ablation in reducing T. mundella proliferation and larvae density in actual field conditions. Therefore, field ablation could not be proven to be an effective control measure to manage the initial pest density and proliferation in the actual young mature oil palm fields especially when those fields were heavily infested. Other means of control methods should therefore be further explored to effectively control the pest, which at the same time is environmental-friendly to maintain a balanced oil palm ecosystem.
\end{abstract}

Keywords: bunch moth, Tirathaba mundella, oil palm, ablation, cultural practice.

Date received: 15 September 2015; Sent for revision: 31 December 2015; Received in final form: 25 October 2016; Accepted: 26 October 2016.

Sarawak Oil Palms Berhad,

124 - 126, Jalan Bendahara,

P. O. Box 547 ,

98000 Miri, Sarawak, Malaysia.

** Department of Agricultural Science, Faculty of Agriculture and Food Science,

Universiti Putra Malaysia Bintulu Sarawak Campus,

Nyabau Road, 97008 Bintulu, Sarawak, Malaysia,

₹ Department of Agricultural Science,

Faculty of Agriculture and Food Science,

Universiti Putra Malaysia,

43400 UPM Serdang, Selangor, Malaysia.

\section{INTRODUCTION}

In South-east Asia, particularly Malaysia and Indonesia, oil palm cultivation has rapidly expanded into degraded peat soils. Currently about 666308 ha of peat lands in Malaysia have been developed for oil palm cultivation and this include 437174 ha in Sarawak, 207458 ha in Peninsular Malaysia and 21406 ha in Sabah (Omar et al., 2010). Such a large area converted from heterogeneous climatic climax vegetation into a mono species crop of oil palm had indirectly upset the natural 
biological balances between hosts, pests and natural enemies of pests, which have been built up over the millennia. Therefore, for oil palm cultivation on peat, pests such as termites, nettle caterpillars, bagworms, bunch moth, rhinoceros beetles and rats have become problematic. Among these common pests, Tirathaba mundella, commonly known as the oil palm bunch moth is becoming a very important bunch feeding pest on oil palm planted on peat soil. The oil palm bunch moth that infested both male and female inflorescences of oil palm was first reported in Peninsular Malaysia by the Department of Agriculture in $1934(\mathrm{Ng}, 1977)$ and later the pest was referred as Tirathaba mundella Walker in his book published in 1968 (Wood, 1968). However, the occurrence of caterpillar damaging the female inflorescences of coconuts in Peninsular Malaysia was first recorded by Richards in 1918 (Corbett, 1932) where he described it as coconut spike moth. The pest was subsequently quoted as Tirathaba sp. near trichogramma Megr. and the biology of this species known as as Tirathaba rufivena Walker was well documented (Corbett, 1932).

Normally, severe infestations are found on palms approaching maturity and young mature palms of 2 to 5 years old planted on peat. Chan (1973) stated that delayed harvesting, absence of castration and poor pollination especially in new immature oil palm estate accentuated the pest infestations. More severe outbreaks of T. mundella can occur on young plantings particularly in peat areas planted with oil palms for the first time. Continuous chronic outbreaks of T. mundella infestation often occur in the first two years of harvesting and estimated crop losses can be as high as 50\% (Lim, 2012).

The typical symptoms of damage by T. mundella caterpillars on the oil palm fruits include consumption of the distal ends of the fruits creating 'scars' and 'pits' on the surface of the fruitlets as well as leaving frass which eventually cover the fruit bunch. In younger bunches, they bore into the developing fruit causing it to fall prematurely, or to develop with a hollow centre instead of a kernel (Wood, 1968). Wood and Ng (1974) discovered that the caterpillars build and move in the infested bunches in tubes of silk which are attached with the granular reddish frass and other detritus. Therefore, presence of granular reddish or dark brown to black frass over the surface of an infested male inflorescence or fruit bunch indicates fresh and old pest activity, respectively. When this pest has infested a palm, male inflorescences, female inflorescences and bunches at various stages of development are attacked. In the case of severe attack on female inflorescences, early bunch abortion can result. The life cycle of T. mundella is short, at about 30 days and therefore it spreads rapidly when proper control is not in place. Wood and $\mathrm{Ng}$ (1974) also recorded that the active larvae stage that feed on oil palm fruits under laboratory condition ranged from 14 to 17 days, followed by pupa stage of $9-12$ days.

Ablation or commonly known as castration or disbudding is a common practice carried out during the immature phase of the oil palm in Malaysia (Mohd Nazeeb et al., 1988). It is based on the assumption that the removal of the developing inflorescences will result in nutrients being channelled for vegetative development resulting in high yields at the commencement of harvesting. Moreover, oil palm planted on peat starts to produce uneconomical bunches as early as 18 months after field planting and if these early small bunches are left unharvested they will become breeding sites for the oil palm bunch moth. Therefore, it is thought important to carry out ablation from 12 to 18 months after field planting at monthly intervals and remove any rotten bunches, to minimise proliferation of the pest in young mature oil palm fields.

Basri et al. (1991) conducted an evaluation of insecticides and cultural practice which is also known as field ablation as control measure for T. rufivena. They concluded that although cultural practice was not an effective treatment, it caused some reduction in the pest population and also bunches with damage. Lim (2012) also stated that good sanitation practices and clean fields will help to minimise the proliferation of T. mundella.

In such instances, the reliability of the cultural control method or field ablation need to be measured and compared with a proven absolute method that generate supporting results. However, there is a marked lack of published information on management of the bunch moth. Therefore, this study was conducted to assess the effect of ablation and non-ablation on the infestation of the oil palm bunch moth in young mature oil palm plantation.

\section{MATERIALS AND METHODS}

\section{Experimental Material and Design}

The field ablation trial was carried out in an oil palm estate situated between latitudes $\mathrm{N}^{\circ} 4.3629870$ and $\mathrm{N}^{\circ} 4.3595942$ and longitudes $\mathrm{E}^{\circ} 114.1340165$ and $\mathrm{E}^{\circ} 114.1365272$ in Sarawak, Malaysia. The estate was planted with 2284.81 ha of matured oil palms ( $>10$ years old) and 314.68 ha of young mature oil palms ( $<5$ years old). The experiment was conducted in a randomised complete block design with 10 replicates of each treatment. Each treatment consisted of 40 rows with 10 to 11 palms in each planting row. All the 20 to 22 palms in the centre of every four rows were selected as sampling palms where the other 11 to 12 palms beside the field drain, on each side of the sampling row served as guard palms. The age of the palms in the trial site were 20 months old at the time of the trial. 


\section{Field Ablation Management}

For control plots, there was no ablation of male, female inflorescences and young bunches. For treatment plots, field ablation was carried out when the palms were 20 months old. A total of three rounds field ablation were carried out by removing all the male and female inflorescences and fruit bunches at palm age of 20 months ( 0 week), 21.5 months ( 6 weeks) and 23 months (12 weeks) respectively using a $10 \mathrm{~cm}$ chisel blade attached to a $150 \mathrm{~cm}$ long wooden pole.

\section{Field Census for T. mundella Infestation}

Immediately prior to first round of ablation which was week 0 , a baseline field census was carried out. The subsequent post-trial census were carried out at bimonthly interval after completing the three rounds of field ablation which were at week 20, week 28 and week 36 starting from the first round of ablation. The detailed field census was carried out by checking all the fruit bunches and male inflorescences regardless of growth stage on each and every sampling palm. The infestation was categorised under three main categories which were no frass, new frass and old frass. The no frass category was represented by un-infested oil palm fruit bunches and male inflorescences. The new frass category was represented by fresh reddish frass found either on oil palm fruit bunches or male inflorescences. The presence of new frass indicated recent pest activities with new attack where larvae with different instars could be found within the fruit bunches and male inflorescences (Figures 1 and 2). The old frass category was represented by old dark brownish frass either on oil palm fruit bunches or male inflorescences which indicated old infestation. The presence of old frass indicated past activities of the pest with old sign of damage and the larvae with

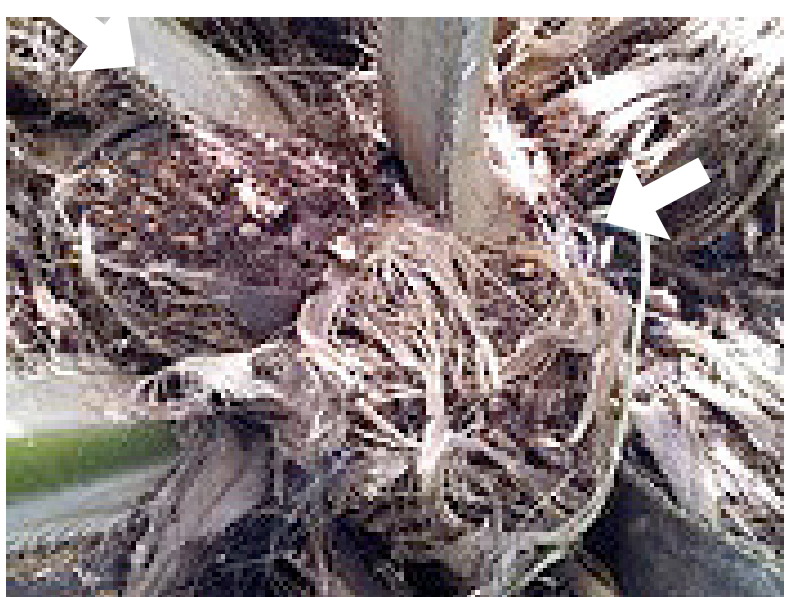

Figure 1. Severe T. mundella infested oil palm palm fruit bunches fully covered by new reddish frass (arrow). different instars could also be found within the fruit bunches and male inflorescences as well.

\section{Field Sampling and T. mundella Larvae Count}

Immediately prior to first round of ablation which was week 0 , a baseline field sampling was carried out. This was followed by another two rounds of field sampling prior to post-trial field sampling which were at week 6 (second round field ablation) and week 12 (third round field ablation). The subsequent post-trial field sampling was carried out at weeks 20, 28 and 36 which were the same period where post-trial field census was conducted as mentioned above. For the field sampling, random samples of three oil palm male inflorescences and five 2 months old young oil palm fruit bunches were being sampled from each treatment and replicate and dissected for larva count in the laboratory. Field samples of male inflorescences and the 2 months old young oil palm fruit bunches were dissected one by one and total larvae of different instars found at the end of the dissection were recorded. After each dissection, the sample was then soaked in clean water for $5 \mathrm{~min}$ to capture the remnant larvae of different instars before the final count.

\section{Statistical Analysis}

Field census and larvae count data. To improve the residual error distribution for field census and larvae count data, an arc-sin square root transformation and logarithmic transformation was applied to the percent of infestation and larvae count data, respectively. All the census data from the three different categories and the total number of larvae count responses to the treatments were subjected to analysis of variance (ANOVA) using statistical analysis system (SAS) version 8.2 (SAS Institute Inc., Cary, NC, USA). Both the mean percentages of

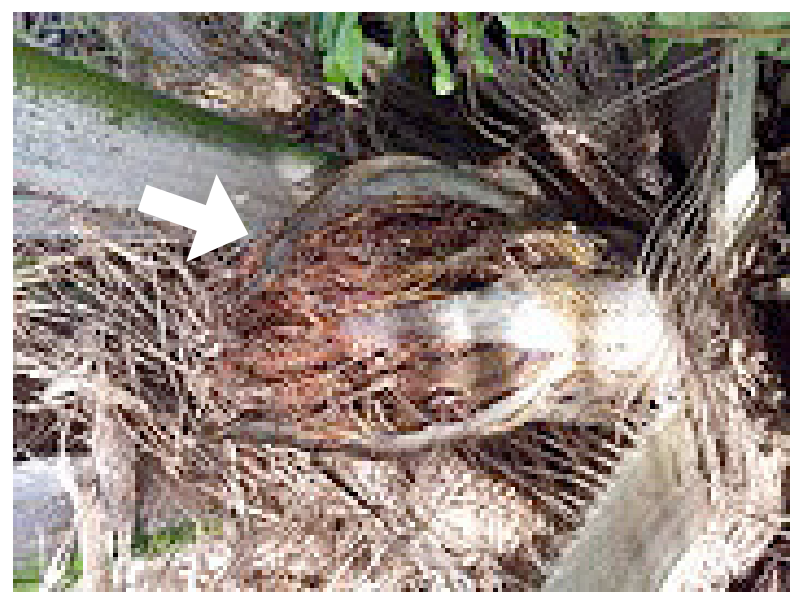

Figure 2. Severe T. mundella infested oil palm palm male inflorescence fully covered by new reddish frass (arrow). 
infestation and mean larvae counts were separated using the Duncan's New Multiple Range Test at a significant level of $\mathrm{p}<0.05$.

\section{RESULTS}

\section{Un-infested Fruit Bunches and Male Inflorescences}

For mean percentage of un-infested fruit bunches and male inflorescences, the census results showed no significant difference between ablated and control fields at week 0 , week 20 and week 36 (Figures 3 and 4). However, at week 28, which was four months after carrying out the ablation trial, the mean percentage of un-infested fruit bunches and male inflorescences in ablated fields were significantly lower as compared with control fields (Figures 3 and 4).

\section{New Infested Fruit Bunches and Male Inflorescences}

New T. mundella infestation for oil palm fruit bunches category after three rounds field ablation consistently showed significantly high mean percentage of new infestation in ablated fields as compared with control, at week 20, week 28 and week 36 (Figure 5). At week 20, although total bunches in ablated fields were low as compared with control fields, the mean percentage of new T. mundella infestation was significantly high (Figure

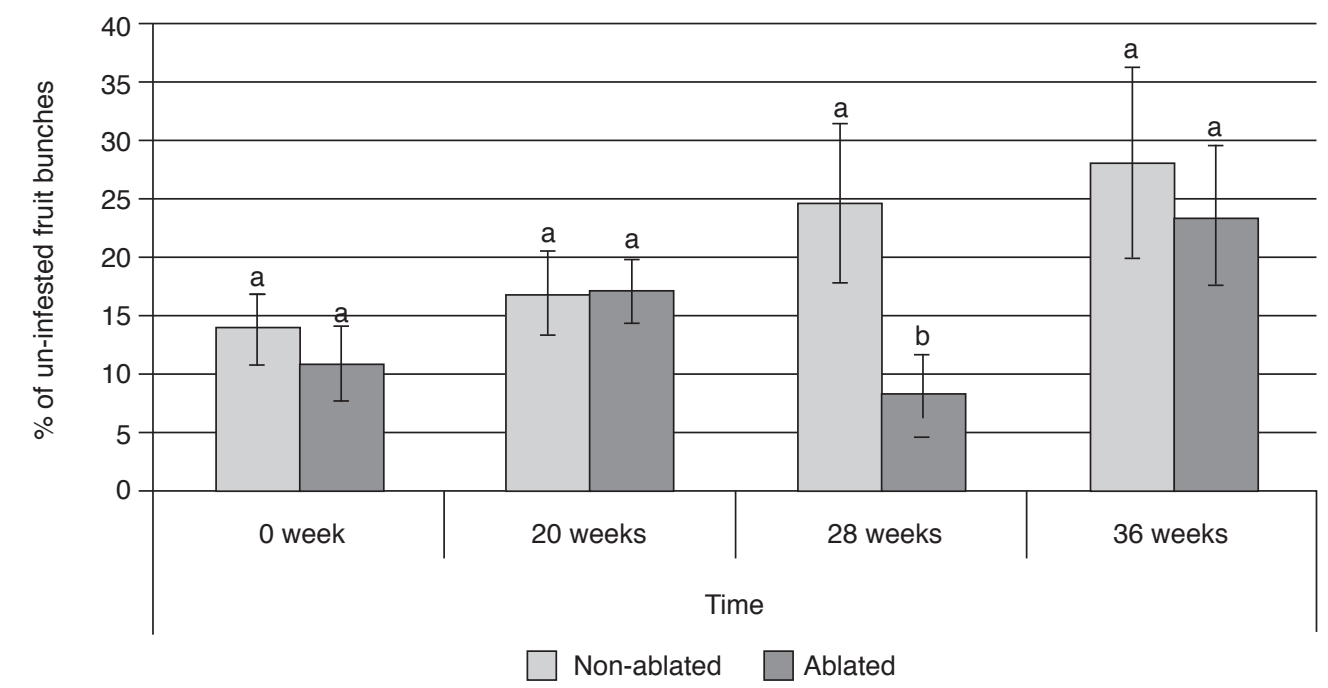

Figure 3. Mean percentages of un-infested fruit bunches category in ablated and non-ablated field under actual field conditions over time. Means with the same letters are not significantly different according to the Duncan's New Multiple Range Test, $(p<0.05)$. The vertical bars represent the standard error of means for 10 replicates.

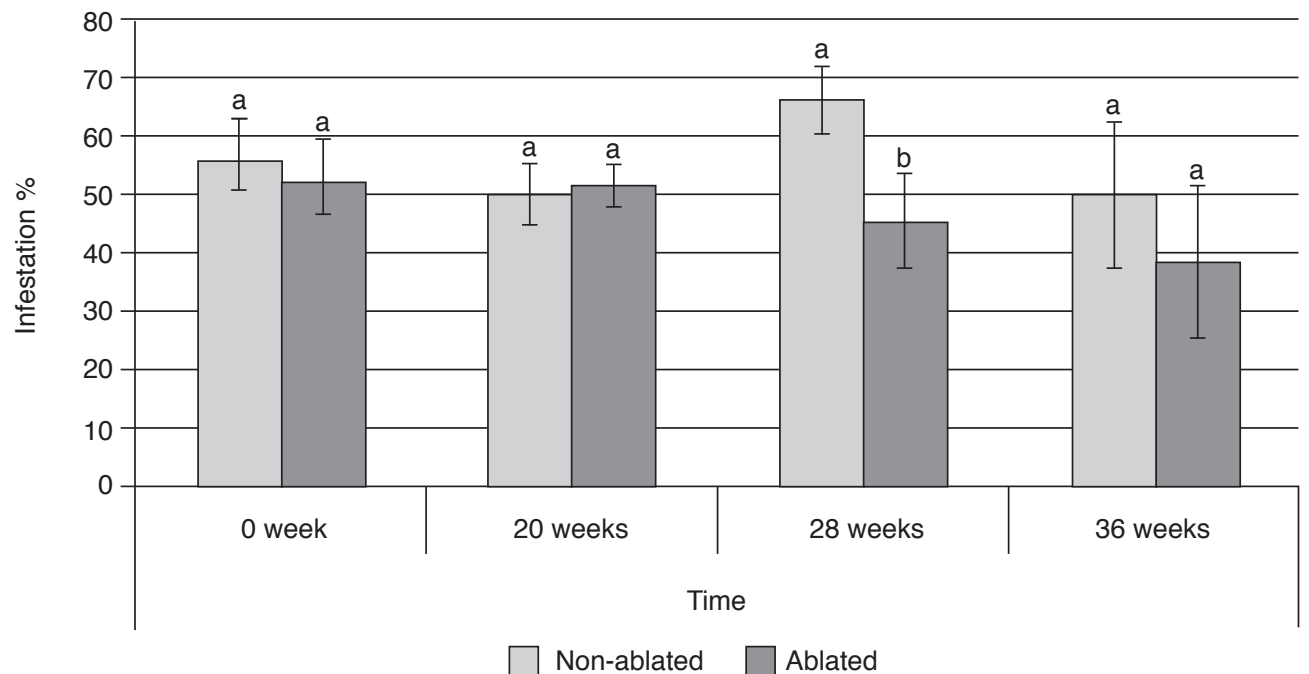

Figure 4. Mean percentages of un-infested male inflorescences in ablated and non-ablated field under actual field conditions over time. Means with the same letters are not significantly difference according to the Duncan's New Multiple Range Test, $(p<0.05)$. The vertical bars represent the standard error of means for 10 replicates. 
5). Nevertheless, mean percentage of new infestation for male inflorescences category in ablated field was also significantly high at week 28 as compared with control (Figure 6).

\section{Old Infested Fruit Bunches and Male Inflorescences}

Over the trial period of nine months, there was no significant difference in mean percentages of old T. mundella infestation between ablated and control fields for male inflorescences category (Figure 7). However, for oil palm fruit bunches category, the mean percentages of old T. mundella infestation in ablated fields were significantly lower than control at week 20 (Figure 8).

In terms of T. mundella larvae density in the actual field conditions for both oil palm fruit bunches and male inflorescences categories, mean larvae counts obtained from seven rounds of sampling showed no significant difference between ablated and control fields except at week 20. At week 20, the mean larvae counts in ablated fields were significantly higher than that of control fields (Figure 9). This result is correlated to the significantly high mean percentages of new infestation found in ablated fields for oil palm fruit bunches category at the same period of assessment (Figure 5).

\section{DISCUSSION}

The primary goal of this research was to determine effects of field ablation as cultural control on T. mundella infestation on young mature oil palm,

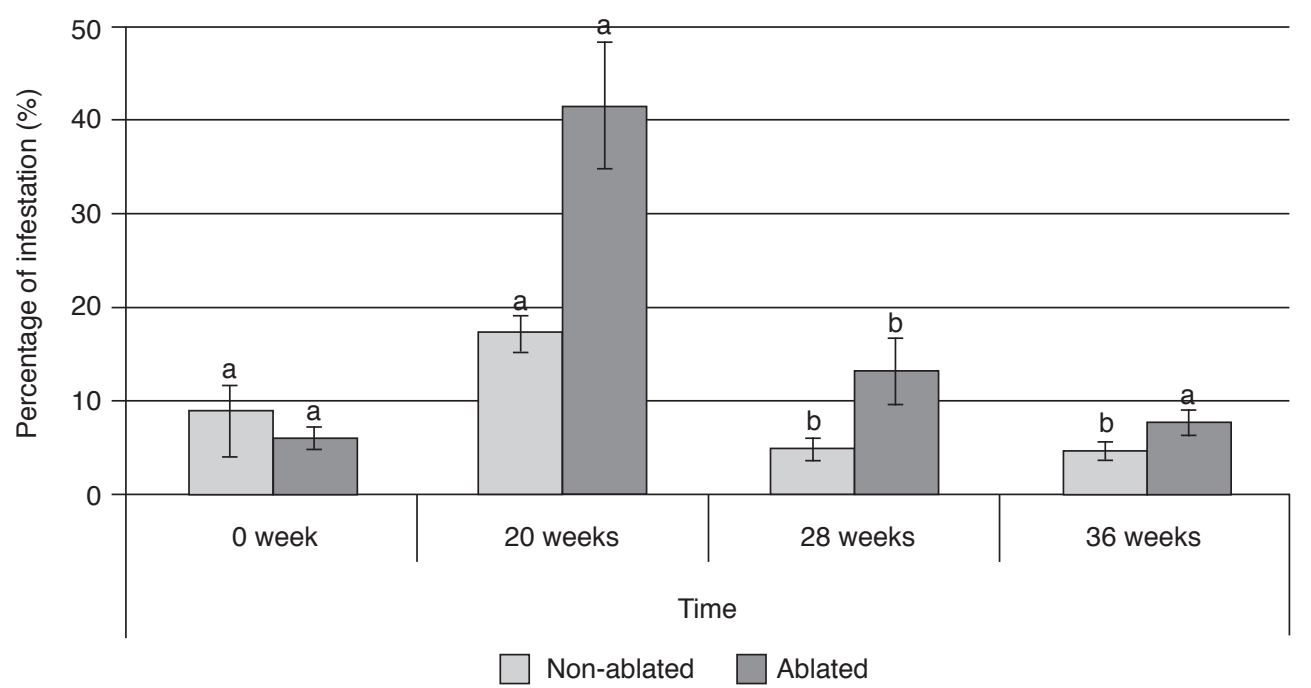

Figure 5. Mean percentages of new T. mundella infestation for bunches category in ablated and non-ablated field under actual field conditions over time. Means with the same letters are not significantly different according to Duncan's New Multiple Range Test, ( $p<0.05)$. The vertical bars represent the standard error of means for 10 replicates.

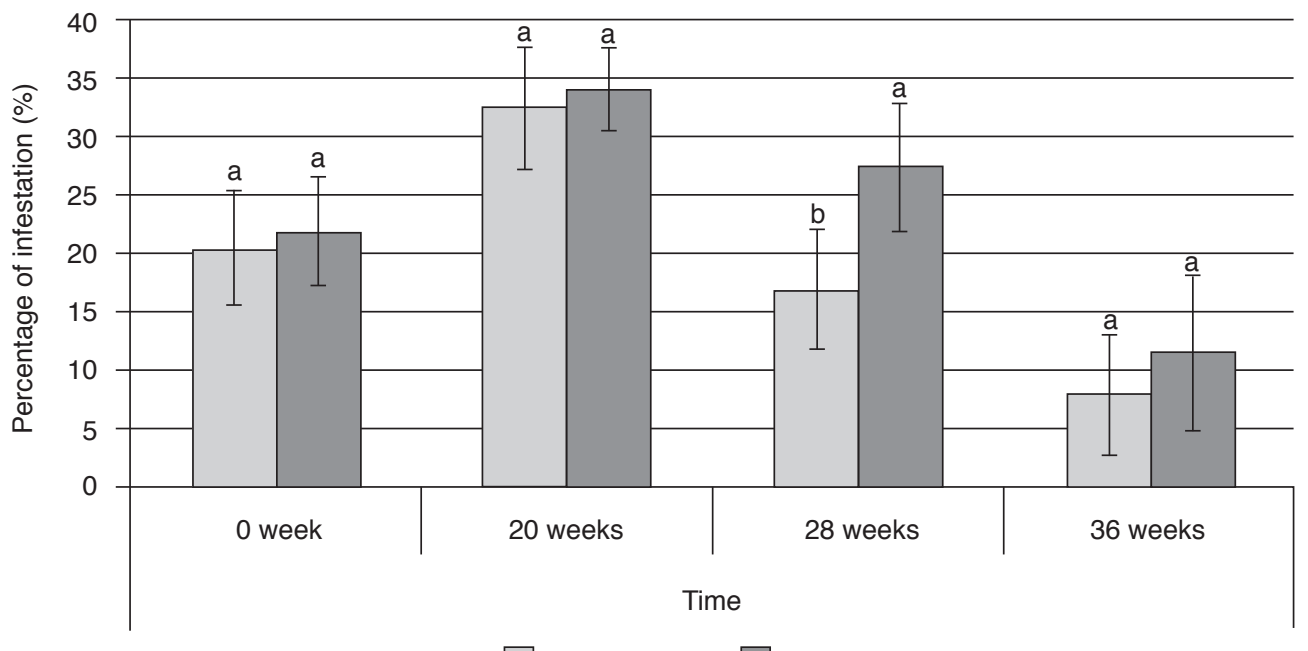

Non-ablated $\square$ Ablated

Figure 6. Mean percentages of new T. mundella infestation for male inflorescences category in ablated and non-ablated field under actual field conditions over time. Means with the same letters are not significantly different according to Duncan's New Multiple Range Test, (p<0.05). The vertical bars represent the standard error of means for 10 replicates. 


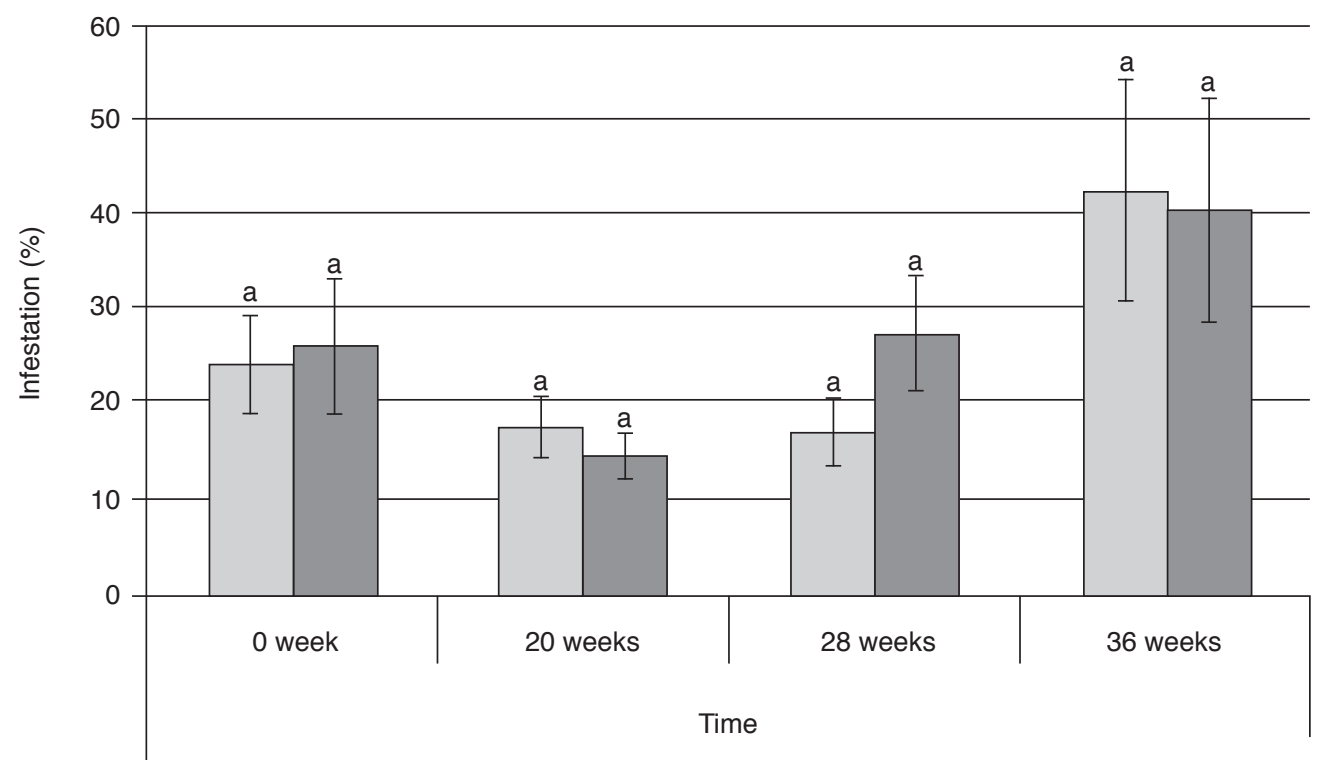

Non-ablated $\square$ Ablated

Figure 7. Mean percentage of old T. mundella infestation for male inflorescences category in ablated and non-ablated field under actual field conditions over time. Means with the same letters are not significantly different according to Duncan's New Multiple Range Test, $(p<0.05)$. The vertical bars represent the standard error of means for 10 replicates.

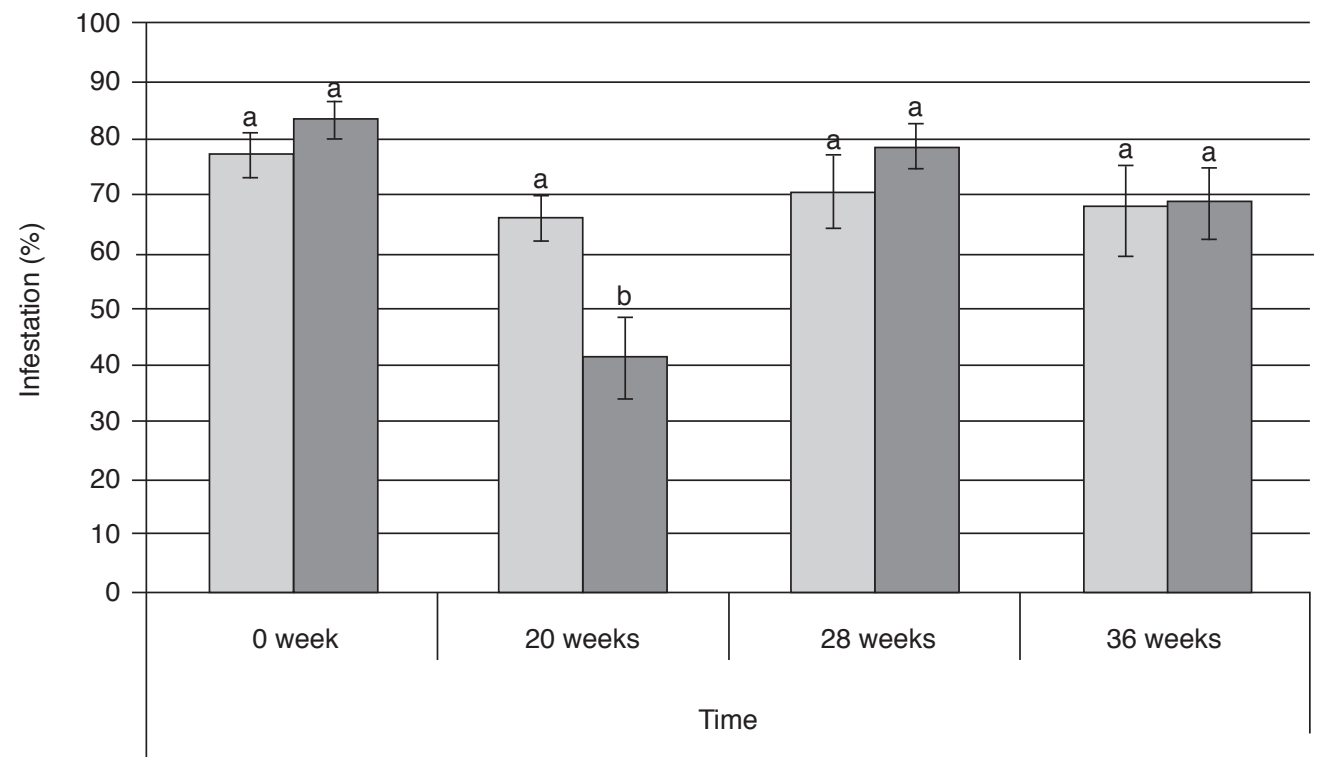

Non-ablated $\square$ Ablated

Figure 8. Mean percentages of old $\mathrm{T}$. mundella infestation for bunches category in ablated and non-ablated field under actual field conditions over time. Means with the same letters are not significantly different according to Duncan's New Multiple Range Test, $(p<0.05)$. The vertical bars represent the standard error of means for 10 replicates.

therefore providing oil palm growers with a better understanding on the necessity of this cultural control against T. mundella under actual field conditions. Field census was being carried out at week 20, which was two months after the third round of field ablation where most of the bunches and male inflorescences on the palms in the ablated fields were about one and a half to two months old. The fields' census results showed more new frass found either on the male inflorescences or fruit bunches of the palms in the ablated fields when compared with control. The presence of significantly high new frass on both young bunches and male inflorescences in the ablated fields strongly indicated that there were more recent pest activities in the ablated fields compared with control fields. This also indicated that T. mundella prefers to feed on young and fresh oil palm fruit bunches as well 


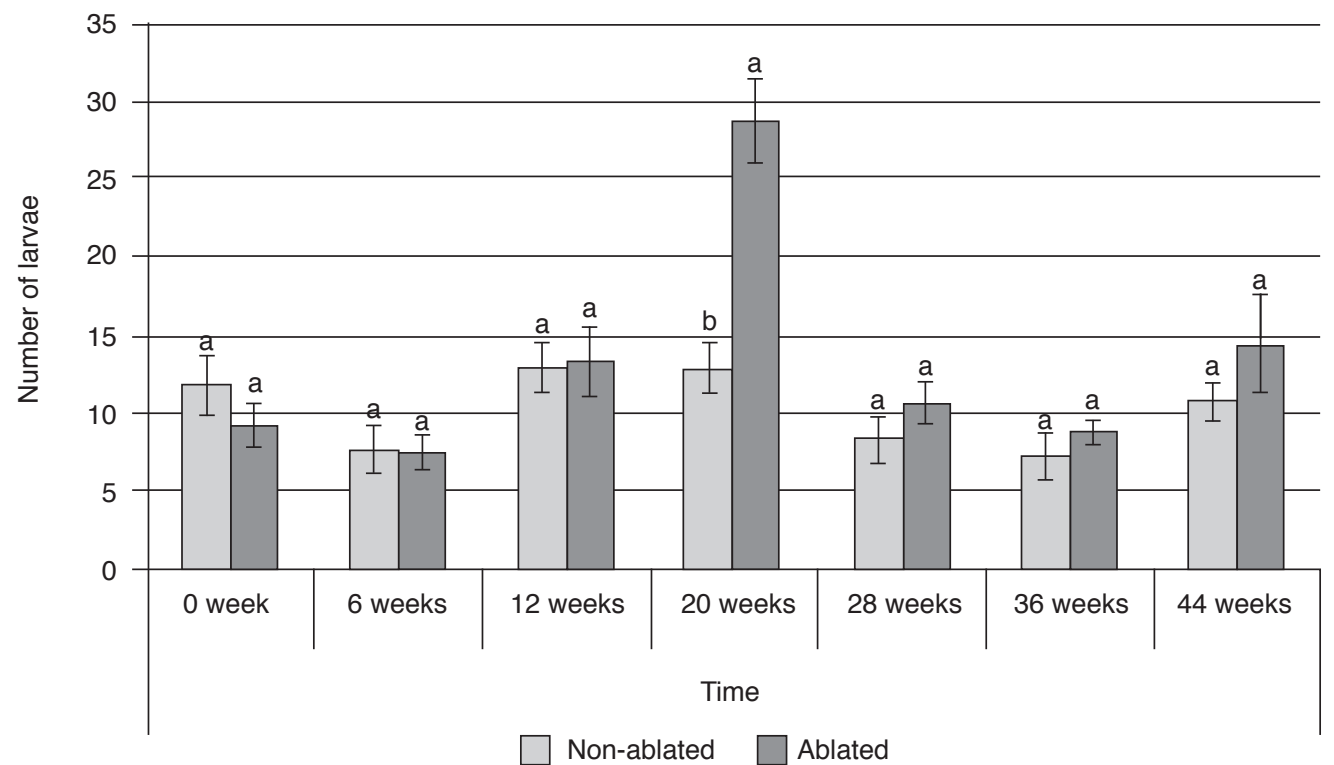

Figure 9. Mean number of T. mundella larvae counts for both male inflorescences and oil palm fruit bunch samples in ablated and non-ablated fields under actual field conditions over time. Means with the same letters are not significantly different according to Duncan's Multiple Range Test, $(p<0.05)$. The vertical bars represent the standard error of means for 10 replicates.

as male inflorescences that were mostly found in ablated fields two months after the ablation had been carried out. This result was further supported by the significant high mean larvae counts found in ablated fields at week 20 when compared with control. The significantly high mean number of larvae in ablated fields at week 20 coincided with the significant increase in mean percentages of new infestation found in the ablated fields. This phenomenon explained that palms in ablated fields with more young fruit bunches and young fresh male inflorescences would attract more larvae of different instars as they could easily bore through the young oil palm fruitlets for the juicy embryocontaining kernel. It is well understood that oil palm kernel is at first liquid, then gelatinous and solidifies at about 100 days after anthesis (Corley and Tinker, 2003). The significantly high density of T. mundella larvae found at week 20 in this study is further confirmed by the earlier researcher who stated that there was a preference of a predominant number of young larvae on the young oil palm fruit bunches of one to two months after formation $(\mathrm{Ng}, 1977)$.

Although there were significantly higher mean percentages of new infestation found in ablated fields at week 20, week 28 and week 36 as compared with control, the mean T. mundella larvae count was only significantly high in ablated fields at week 20 . The density of the T. mundella larvae in the sampled bunches and male inflorescences from ablated fields appeared to be higher than samples from control fields at week 20 . This could be due to the oviposition habit of T. mundella where the adult moths prefer to lay their egg masses on the under surfaces of parienths of young fruits of one to two months after formation instead of other stages of female inflorescences which is before receptive stage, at flowering stage, immature fruits of three to four months after formation, ripe fruits $(\mathrm{Ng}, 1977)$ and the field conditions in ablated field at week 20 where most of the bunches are at the stage of about 1-2 months old after third round of ablation being carried out.

However, at week 28 and week 36, where more young and new bunches and male inflorescences were being formed in the ablated fields, the T. mundella larvae of different instars tend to migrate within the fields. Consequently, there was no significant differences in terms of T. mundella larvae count from the samples obtained from ablated fields when compared with control although there were still significantly higher new T. mundella infestations being detected in ablated fields than control.

The results of mean percentages of old, new infestation and larvae count obtained from this field ablation trial, indicated that there was no obvious advantage of ablation in reducing the $T$. mundella infestation as well as pest density. In fact, the ablated fields had higher new pest infestation and pest density. Therefore, it may not be justifiable for oil palm growers to carry out field ablation as a cultural practice for controlling T. mundella in young mature oil palm plantation. However, further trials which involved both ablation exercise and bioinsecticide spraying using Bacillus thuringiensis at two months' interval starting from month 24 , which 
is one month after the last round of field ablation being carried out is suggested. This could be able to help protect most of the bunches in the field before actual harvesting commence at month 30 .

\section{CONCLUSION}

This field ablation trial demonstrated that estate cultural practice with only three rounds of field ablation did not significantly reduce both $T$. mundella infestation and larvae density in actual field conditions if speedy application of insecticide was not imposed as an integrated approach to control this pest. It is believed that insecticide application may still be the viable option to control T. mundella in the oil palm plantations especially during young maturity phase. However, good field sanitation which includes removing all the uneconomical fruit bunches, male inflorescences and dry fronds during early stage of maturity would result in more nutrients being chanelled for vegetative development, which will result in high initial yields at the commencement of harvesting (Mohd Nazeeb et al., 1988) should be continued. Further trials should be carried out to evaluate the effectiveness of combining both good field sanitation practices and chemical or biological insecticides as a good integrated approach to avoid outbreak situation in young mature oil palm plantation planted on peat.

\section{ACKNOWLEDGEMENT}

The authors would like to thank Sarawak Oil Palms Berhad, Miri, Sarawak, Malaysia for support of field works, and to consultant agronomist, Ong Kim Pin for his interest in this study. The facilities and technical supports from Universiti Putra Malaysia Bintulu Campus, Sabah, Malaysia are gratefully acknowledged.

\section{REFERENCES}

BASRI, M W; SHARMA, M and NORMAN, K (1991). Field evaluation of insecticides and a cultural practice against the bunch moth, Tirathaba rufivena in a mature oil palm plantation. Elaeis, 3(2): 355-362.

CHAN, C O (1973). Some notes on the oil palm bunch moth (Tirathaba mundella Walk.) and its control. Advances in Oil Palm Cultivation (Wastie, R L and Earp, D A eds.). Incorporated Society of Planters, Kuala Lumpur. p. 396-401.

CORBETT, G H (1932). Insects of Coconuts in Malaya. Department of Agriculture, Straits Settlements and Federated Malay State. p. 85-88.

CORLEY, R H V and TINKER, P B (2003). The Oil Palm. Fourth ed. Blackwell Science Ltd. p. 45-46.

LIM, K H (2012). Integrated pest management of Tirathaba bunch moth on oil palm planted on peat. The Planter, 88: 97-104

LIM, K H; LIM, S S; PARISH, F and SUHARTO, R (eds) (2012). RSPO Manual on Best Management Practices (BMPs) for Existing Oil Palm Cultivation on Peat. RSPO, Kuala Lumpur.

MOHD, NAZEEB; A LETCHUMANAN and LOONG, S G (1988). A study of ablation of oil palms in Peninsular Malaysia after the introduction of the pollinating weevils (E. kamerunicus). The Planter, 64: 245-251.

NG, K Y (1977). Bionomics of T. mundella, A Pest of Oil Palm. Master of Agriculture Science thesis, University of Malaya, Kuala Lumpur. p. 30-37.

OMAR, W; ABD AZIZ, N; MOHAMMED, A T; HARUN, M H and DIN, A K (2010). Mapping of oil palm cultivation on peatland in Malaysia. $M P O B$ Information Series No. 473.

WOOD, B J and NG, K Y (1974). Studies on the biology and control of oil palm bunch moth, $T$. mundella Walk. (Lepidoptera: Pyralidae). Malay. Agric. J., 49(3): 310-331.

WOOD, B J (1968). Pests of Oil Palms in Malaysia and their Control. The Incorporated Society of Planters, Kuala Lumpur. p. 111-113. 